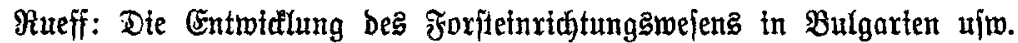

\begin{tabular}{|c|c|c|c|c|c|c|}
\hline \multirow[t]{2}{*}{ Berufe } & \multicolumn{3}{|c|}{$\begin{array}{l}\text { Bropbetriebe } \\
\text { in ben Sabren }\end{array}$} & \multicolumn{3}{|c|}{ 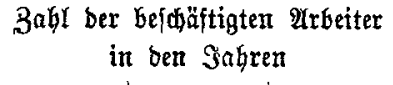 } \\
\hline & 1909 & 1921 & 1924 & 1909 & 1921 & 1924 \\
\hline ägeinbuftrie. & 6 & 2 & 5 & 426 & 225 & 963 \\
\hline Übelinduftrie & 8 & 19 & 21 & 203 & 493 & 405 \\
\hline agnersimerfe. . & 2 & 1 & 1 & 28 & 5 & 10 \\
\hline ottideret umb andere. & 2 & 1 & - & 13 & 11 & - \\
\hline $\operatorname{mm}=\mathfrak{n n b}$ anbere 2 berle. . . & - & 1 & 1 & - & - & 23 \\
\hline ifriften= und Befentwerte & - & - & - & - & 36 & - \\
\hline \$olżnouiltie & 18 & 24 & 28 & 670 & 770 & 1401 \\
\hline \multicolumn{7}{|c|}{ 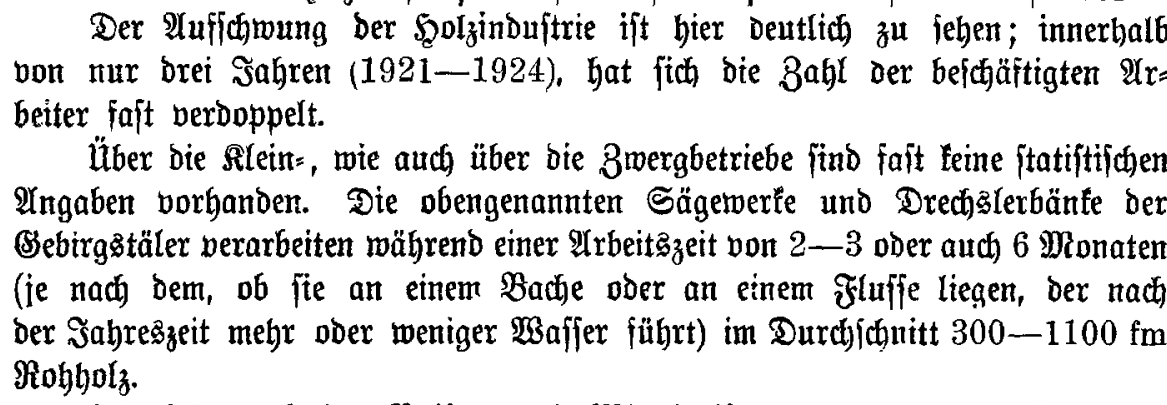 } \\
\hline $\begin{array}{l}\text { Die Sägemerfe bes } \mathfrak{B a l} \\
\text { ưbholz, meiften } \mathfrak{B} \text { Buchenholz }\end{array}$ & & & & & & \\
\hline
\end{tabular}

(Sdilutí folgt.)

\title{
III. Büheranjeigen.
}

Nr. 31.

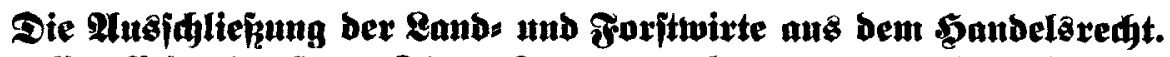

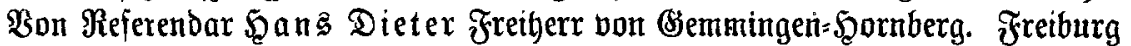
1928. Diji.

Mer fïch für bie Stellung ber \&and= und Forftrixtichaft zum Şandel und zum \$̧andelagejeb̧buch intereffiert, findet in ber etwa 60 Seiten umfajfenden Arbeit lejensmerte Bsedanten.

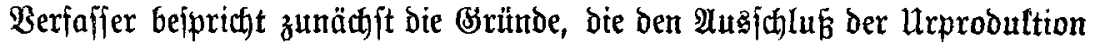

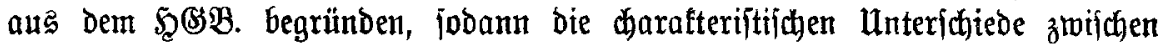
Şanbel und Urprobuttion, um zum Shluffe auf bie Innäherung betber (Ses biete, die wir $z . \mathfrak{B}$. in Der fortif,reitenden $\mathfrak{B u c h f u ̈ h r u n g}$ bei ber Urprobuttion fitch vollzieben jehen, aujmerfiam zu machen. Frhr. v. (Sö öler, Foritrat. 